\title{
Formulation of a Novel Tianeptine Sodium Orodispersible Film
}

\author{
Doaa Ahmed El-Setouhy ${ }^{1,2}$ and Nevine Shawky Abd El-Malak ${ }^{1}$
}

\begin{abstract}
Received 14 December 2009; accepted 13 May 2010; published online 8 June 2010
Abstract. The present investigation was undertaken with the objective of formulating orodispersible film(s) of the antidepressant drug tianeptine sodium to enhance the convenience and compliance by the elderly and pediatric patients. The novel film former, lycoat NG73 (granular hydroxypropyl starch), along with different film-forming agents (hydroxypropyl methyl cellulose, hydroxyethyl cellulose, and polyvinyl alcohol), in addition to three film modifiers; namely, maltodextrin, polyvinyl pyrrolidone K90 and lycoat RS780 (pregelatinized hydroxypropyl starch) were evaluated. Eight formulae were prepared by the solvent-casting method; and were evaluated for their in vitro dissolution characteristics, in vitro disintegration time, and their physico-mechanical properties. The promising orodispersible film based on lycoat NG73 (F1); showing the greatest drug dissolution, satisfactory in vitro disintegration time and physico-mechanical properties that are suitable for orodispersible films, was evaluated for its bioavailability compared with a reference marketed product (Stablon ${ }^{\circledR}$ tablets) in rabbits. Statistical analysis revealed no significant difference between the bioavailability parameters $\left(C_{\max }(\mathrm{ng} / \mathrm{ml}), t_{\max }(\mathrm{h})\right.$, $\mathrm{AUC}_{0-t}\left(\mathrm{ng} \mathrm{hml}^{-1}\right)$, and $\left.\mathrm{AUC}_{0-\infty}\left(\mathrm{ng} \mathrm{hml}^{-1}\right)\right]$ of the test film (F1) and the reference product. The mean ratio values (test/reference) of $C_{\max }(89.74 \%), \mathrm{AUC}_{0-t}(110.9 \%)$, and $\mathrm{AUC}_{0-\infty}(109.21 \%)$ indicated that the two formulae exhibited comparable plasma level-time profiles. These findings suggest that the fast orodispersible film containing tianeptine is likely to become one of choices for acute treatment of depression.
\end{abstract}

KEY WORDS: bioavailability from orodispersible films and tablets; fast-dissolving films; orodispersible films; solvent-casting method; tianeptine sodium.

\section{INTRODUCTION}

Fast-dissolving drug delivery systems are rapidly gaining interest in the pharmaceutical industry. These systems either dissolve or disintegrate generally within a minute, without the need for water or chewing (1).

The introduction of fast-dissolving dosage forms has solved some of the problems encountered in administration of drugs to the pediatric and elderly patients. Some elderly patients may not be able to swallow a daily dose of antidepressant and a schizophrenic patient can hide a conventional tablet under his or her tongue to avoid their daily dose of an atypical antipsychotic $(2,3)$.

Recently, fast-dissolving films are gaining interest as an alternative of fast-dissolving tablets. The films are designed to dissolve upon contact with a wet surface, such as the tongue, within a few seconds, meaning the consumer can take the product without the need for additional liquid. This convenience provides both a marketing advantage and increased patient compliance (4). Fast-dissolving films are generally

\footnotetext{
${ }^{1}$ Department of Pharmaceutics and Industrial Pharmacy, Faculty of Pharmacy, Cairo University, Kasr El-Aini Street, Cairo, 11562, Egypt.

${ }^{2}$ To whom correspondence should be addressed. (e-mail: doaaahmed@ hotmail.com)
}

constituted of plasticized hydrocolloids or blends made thereof. Formulation of these systems is usually simple; either by solvent-casting where the polymer and drug are dissolved (or dispersed) in a solvent (often ethanol or water) and a film is cast by solvent evaporation or by hot melt extrusion. Polyvinyl alcohol, polyvinyl pyrrolidone, maltodextrin, microcrystalline cellulose, Hydroxypropyl methyl cellulose, modified starch, chitosan, gums, or blends of these polymers have been used for film production (1,4-8).

Lycoat NG 73® is a novel granular hydroxypropyl starch polymer that has been designed specially for orodispersible films (ODFs). Lycoat NG 73 disperses easily in cold water without formation of lumps. Simple cooking by heating will develop its film-forming ability; it gives a homogenous solution as viscosity develops progressively by cooking thus preventing formation of lumps and agglomerates. It can be used as the sole film-forming polymer to formulate ODF with excellent functionality without the need of additional filmforming agent (9).

Tianeptine sodium is a water soluble antidepressant effective against anxiety accompanying mood disorders. Its antidepressant and anxiolytic properties and its action on somatic complaints claimed to make the drug particularly suitable for the treatment of the entire range of depressive symptomatology $(10,11)$. In addition, it was found that tianeptine possesses also anticonvulsant effect (12) and analgesic effect (13). Tianeptine is claimed to be a useful 
drug for the treatment of seizures, anxiety, and various painful symptoms other than depression (14).

The present investigation was undertaken with the objective of formulating ODFs of tianeptine sodium to be potentially useful for treatment of acute depression and to enhance the convenience and compliance by the elderly and pediatric patients.

\section{MATERIALS AND METHODS}

\section{Materials}

Tianeptine sodium was obtained as a gift from laboratories of Servier (Gidy, France). Lycoat NG73 (granular hydroxypropyl starch), Lycoat RS780 (pregelatinized hydroxypropyl starch), and Maltodextrin (MD) were obtained as gifts from Roquette Co. (France). Hydroxypropyl methyl cellulose (HPMC; 2910, 4000cp, Tama, Tokyo, Japan). Polyvinyl pyrrolidone K90 (PVP K90; Fluka AG, Buchs SG, Switzerland). Hydroxyethyl cellulose (HEC; gift from El-Nile Pharmaceutical Co., Cairo, Egypt). Polyvinyl alcohol (PVA; M.wt. 16,000; Fluka Chemie GmbH CH-9471 Buchs, Switzerland). Propylene glycol (PG; analytical grade), and Menthol (El-Nasr Co for Pharmaceutical Industries, Cairo, Egypt). Acetonitrile highperformance liquid chromatography (HPLC) grade, Methanol HPLC grade (Merk Co, USA). Stablon ${ }^{\circledR}$ tablets $(12.5 \mathrm{mg}$ tianeptine sodium tablets, Servier, Egypt).

\section{Preparation of Tianeptine Sodium Orodispersible Films}

Four film-forming materials were used, namely, Lycoat NG73, HPMC, HEC, PVA. MD, PVP K90, and Lycoat RS780 were used as film modifiers, and PG as a plasticizer. The films were prepared by solvent-casting method. The film-forming material was dissolved in cold (HPMC, HEC) or hot distilled water (PVA) containing film modifier, the plasticizer PG, and tianeptine sodium (in case of medicated films). The polymeric solutions were left until the removal of air bubbles (if present). Menthol was added as alcoholic solution to the polymeric mixture. Twenty milliliters of the solution was casted into $7.1 \mathrm{~cm}$ glass Petri dish and left to dry in oven at $40^{\circ} \mathrm{C}$ (or $50^{\circ} \mathrm{C}$ in case of PVA films).
For preparation of Lycoat NG73 films, the novel polymeric material was cooked into hydroalcholic solution containing the drug (medicated film) and $\mathrm{PG}$ at $70^{\circ} \mathrm{C}$ for $3 \mathrm{~h}$. Menthol was added as alcoholic solution to the mixture after being cooled down to $50^{\circ} \mathrm{C}$, and then $20 \mathrm{ml}$ of the mixture was poured into glass Petri dish and left to dry in oven at $40^{\circ} \mathrm{C}$.

Preliminary trials (plain films) were undertaken for designing the orodispersible films where the effect of various concentrations of the different film-forming agents and film modifiers on the characteristics of the films was assessed. The prepared films were evaluated for surface perfection, smoothness, ease of separation from Petri dish without rupturing, folding or cracking (peelability). The composition of selected films for preparation of medicated ODFs is shown in Table I.

\section{Thickness Measurements}

The thickness of each film was measured at five different locations (centre and four corners) using Vernier caliper micrometer (Shanghai, China). Data are represented as a mean \pm SD of five replicate determinations.

\section{Determination of Moisture Uptake}

Films were cut into $2 \times 2 \mathrm{~cm}$ square strips $\left(4 \mathrm{~cm}^{2}\right)$. The moisture uptake by the films $(n=3)$ was determined by exposing them to an environment of $75 \%$ relative humidity $(\mathrm{RH})$ at room temperature $\left(25 \pm 2^{\circ} \mathrm{C}\right)$ for 1 week $(15,16)$. The uptake of moisture by the films was measured and calculated as percent increase in weight.

\section{In vitro Disintegration Time}

The test was performed using the method mentioned by Mutasem et al. (17) with slight modification. The film size required for dose delivery $(2 \times 2 \mathrm{~cm})$ was placed on a glass Petri dish containing $10 \mathrm{~mL}$ of distilled water. The time required for the film to break was noted as in vitro disintegration time. Three replicates were done.

Table I. Composition of Different Orodispersible Films Containing Tianeptine Sodium

\begin{tabular}{|c|c|c|c|c|c|c|c|c|}
\hline \multirow[b]{2}{*}{ Ingredients $^{a}$} & \multicolumn{8}{|c|}{ Formulae } \\
\hline & $\mathrm{F} 1$ & $\mathrm{~F} 2$ & F3 & $\mathrm{F} 4$ & F5 & F6 & F7 & F8 \\
\hline Lycoat NG73 & 15 & & & & & & & \\
\hline Polyvinyl alcohol & & & 5 & 5 & & & & \\
\hline Hydroxypropyl methyl cellulose & & 4 & & & & & & \\
\hline Hydroxyethyl cellulose & & & & & 3 & 3 & 1.5 & 3 \\
\hline Alcohol & 15 & & & & & & & \\
\hline Propylene glycol & 7.5 & 7.5 & 7.5 & 7.5 & 7.5 & 7.5 & 7.5 & 7.5 \\
\hline Maltodextrin & & 1.25 & 1.25 & 2.5 & 1.25 & & & 2.5 \\
\hline Lycoat RS780 & & & & & & 1.25 & & \\
\hline Polyvinyl pyrrolidone K 90 & & & & & & & 10 & \\
\hline Menthol $^{b}$ & 0.5 & 0.5 & 0.5 & 0.5 & 0.5 & 0.5 & 0.5 & 0.5 \\
\hline Distilled Water to & 100 & 100 & 100 & 100 & 100 & 100 & 100 & 100 \\
\hline
\end{tabular}

The concentration of the drug was $12.5 \mathrm{mg} / 4 \mathrm{~cm}^{2}$ of the film

${ }^{a}$ The amounts are in grams

${ }^{b}$ Added as $1 \mathrm{ml}$ solution in ethyl alcohol 
Table II. Physico-mechanical Properties of Different Tianeptine Sodium Orodispersible Films

\begin{tabular}{cccccc}
\hline Formulae & $\%$ Drug content ${ }^{a}$ & DT $(\mathrm{Sec})^{b}$ & ${\text { Thickness }(\mathrm{mm})^{a}}^{b}$ & TS $\left(\mathrm{N} / \mathrm{cm}^{2}\right)^{b}$ & $\% \mathrm{E}(\mathrm{cm} \%)^{b}$ \\
\hline F1 & $102.70 \pm 3.05$ & $60.67 \pm 1.15$ & $0.32 \pm 0.044$ & $2.03 \pm 0.012$ & $91.08 \pm 3.17$ \\
F2 & $97.27 \pm 0.74$ & $57.67 \pm 2.52$ & $0.10 \pm 0$ & $2.47 \pm 0.1$ & $81.69 \pm 1.64$ \\
F3 & $103.93 \pm 2.54$ & $123.00 \pm 4.36$ & $0.37 \pm 0.044$ & $11.81 \pm 2.5$ & $39.57 \pm 4.009$ \\
F4 & $98.79 \pm 0.94$ & $90.00 \pm 10$ & $0.36 \pm 0.054$ & $7.23 \pm 0.27$ & $36.71 \pm 1.59$ \\
F5 & $97.99 \pm 0.61$ & $62.67 \pm 8.33$ & $0.12 \pm 0.027$ & $1.82 \pm 0.02$ & $65.50 \pm 5.02$ \\
F6 & $101.81 \pm 4.17$ & $44.33 \pm 5.13$ & $0.19 \pm 0.022$ & NA & NA \\
F7 & $98.36 \pm 1.66$ & $60.00 \pm 4$ & $0.22 \pm 0.027$ & $2.47 \pm 0.32$ & $144.05 \pm 2.75 \pm 3.38$ \\
F8 & $102.64 \pm 4.22$ & $45.00 \pm 5$ & $0.11 \pm 0.022$ & $0.99 \pm 0.22$ & $69.95 \pm 3.61$ \\
\hline
\end{tabular}

$T S$ tensile strength, $E M$ modulus of elasticity, $\% E \%$ elongation, $D T$ disintegration time, $N A$ not applicable

${ }^{a}$ Values are expressed as mean $\pm \mathrm{SD} ; n=5$

${ }^{b}$ Values are expressed as mean $\pm \mathrm{SD} ; n=3$

\section{HPLC Analysis}

The HPLC procedure described by Alaa Khedr (11) was adopted with slight modification. Stock solution containing $100 \mu \mathrm{g} \mathrm{ml}^{-1}$ tianeptine sodium was prepared in the mobile phase. The calibration curve was constructed in $10-60 \mu \mathrm{g} \mathrm{ml}^{-1}$ range $\left(10,20,30,40,50\right.$, and $\left.60 \mu \mathrm{g} \mathrm{ml}^{-1}\right)$. The column was Spherisorb ODS1, $5 \mu \mathrm{m}, 4.6 \times 150 \mathrm{~mm}$ (Waters Corp., Ireland). The mobile phase was prepared by mixing equal amounts of methanol and mixture of acetonitrile, water, and phosphate buffer $\mathrm{pH} 5.4$ (3.7:2.3:4). The flow rate was $0.75 \mathrm{ml} / \mathrm{min}$. The effluent was monitored at $254 \mathrm{~nm}$ using a SPD-10AVP, UV visible detector. All assays were done at room temperature $\left(25 \pm 2^{\circ} \mathrm{C}\right)$. The estimation method was validated for linearity, precision, accuracy, and specificity.

\section{Drug Content Determination}

One square centimeter samples representing five different regions (center and four corners) within the film were cut, and dissolved in an appropriate amount of the mobile phase and the solution was filtered through $0.45 \mu \mathrm{m}$ membrane filter and tianeptine was assayed by the previously mentioned HPLC method.

\section{In Vitro Dissolution Study}

The in vitro dissolution test was performed using the USPXXX dissolution apparatus I. The dissolution studies were carried out at $37 \pm 0.5^{\circ} \mathrm{C}$; with stirring speed of $100 \mathrm{rpm}$ in $400 \mathrm{ml}$ freshly distilled water $(18,19)$. The film size required for dose delivery $(2 \times 2 \mathrm{~cm})$ was used. Three milliliters aliquots of dissolution media were collected at predetermined time intervals of $2,4,6,8$, and $10 \mathrm{~min}$ and replaced with equal volumes of distilled water. The collected samples were filtered through $0.45 \mu \mathrm{m}$ membrane filter and the concentration of the dissolved tianeptine sodium was determined using the HPLC technique. The results were the average of three determinations.

\section{Tensile Strength}

Chacillon force measurement apparatus (Greenspora, NC 27409, India) was used. The apparatus has two clamps, the upper one is fixed and the lower is movable. The film sample $(0.5 \times 3 \mathrm{~cm})$ was clamped between the two clamps. The force at tearing and elongation were determined. The percent elongation $(\% E)$ was calculated using the following equation:

$$
\% E=\left\{\left(L_{\mathrm{s}}-L_{\mathrm{o}}\right) / L_{\mathrm{o}}\right\} \times 100
$$

Where $L_{\mathrm{o}}$ is the original length and $L_{\mathrm{s}}$ is the length of the film after elongation.

The modulus of elasticity of films was calculated from the equation:

$$
F / A=\operatorname{EM}\left\{\left(L_{\mathrm{s}}-L_{\mathrm{o}}\right) / L_{\mathrm{o}}\right\}
$$

Where $F$ = breaking load $(N), A=$ cross-sectional area of the film, and Modulus of Elasticity (EM) is the modulus of elasticity.

Table III. Intra-day, Inter-day Precision and Accuracy of the HPLC Method Used for the Determination of In Vitro Tianeptine Sodium

\begin{tabular}{|c|c|c|c|c|c|}
\hline \multirow[b]{2}{*}{ Concentration $(\mu \mathrm{g} / \mathrm{ml})$} & \multicolumn{2}{|c|}{ Precision C.V.\% } & \multicolumn{3}{|c|}{ Accuracy } \\
\hline & Intra-day & Inter-day & $\mathrm{C}_{\text {theoretical }}$ & $\mathrm{C}_{\text {measured }}$ & $\% \mathrm{RE}$ \\
\hline 10 & 1.97596 & 1.39142 & 10 & 9.86 & -1.42 \\
\hline 20 & 6.86578 & 1.85418 & 20 & 19.49 & -2.54 \\
\hline 30 & 4.91650 & 2.14179 & 30 & 28.78 & -4.08 \\
\hline 40 & 3.88590 & 1.39157 & 40 & 39.71 & -0.73 \\
\hline 50 & 4.31644 & 2.73502 & 50 & 48.76 & -2.48 \\
\hline 60 & 4.48191 & 0.89821 & 60 & 60.66 & 1.09 \\
\hline
\end{tabular}
Concentration 


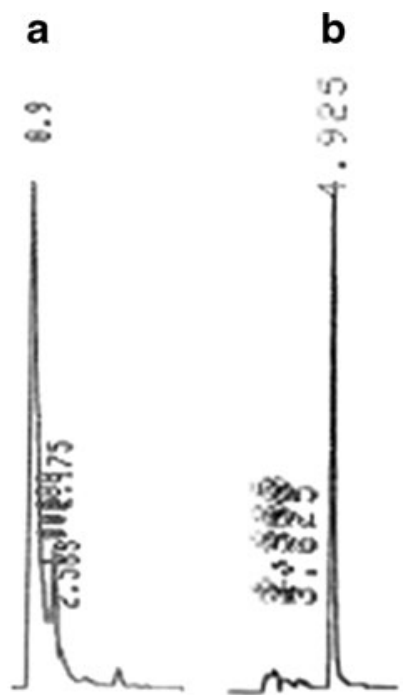

Fig. 1. Representative chromatograms of a blank excipients solution (a) and of standard drug solution $(20 \mu \mathrm{g} / \mathrm{ml})$ (b) at $254 \mathrm{~nm}$

\section{Differential Scanning Calorimetry}

The differential scanning calorimetry (DSC) measurements were performed using a Shimadzu DSC-60 (Kyoto, Japan). Film Samples weighing approximately $5 \mathrm{mg}$ were cut, sealed in aluminum pans, and analyzed in an atmosphere of nitrogen at flow rate of $25 \mathrm{ml} / \mathrm{min}$. A temperature range of $0^{\circ} \mathrm{C}$ to $200^{\circ} \mathrm{C}$ was used, and the heating rate was $10^{\circ} \mathrm{C} / \mathrm{min}$. DSC of plain drug and other excipients in the formulations was also performed.

\section{Bioavailability Study of Selected Tianeptine Sodium ODF}

\section{Study Design}

The study was conducted in accordance with the principles of Laboratory Animal care and was approved by institutional ethics committee of the University. Six male rabbits (weighed $2.5 \pm 0.2 \mathrm{~kg}$ ) were selected for this study. All the rabbits were healthy during the period of the experiment. The rabbits were fasted overnight before administration of selected ODF (F1) or marketed tianeptine tablets (Stablon $\left.{ }^{\circledR}\right)$, but had a free access to water. The study was a simple crossover design with two weeks washout period. The rabbits were randomly divided into two groups (A and B) each of three rabbits. The selected ODF (F1, $\left.4 \mathrm{~cm}^{2}\right)$ was administered orally to group A, where the rabbits were anaesthetized with intravenous injection of pentobarbital in a dose of $25 \mathrm{mg} / \mathrm{kg}$ (20). The rabbits were then positioned on a table with the lower jaw supported in a horizontal position and the ODF was carefully placed on the rabbit's tongue $(21,22)$. The rabbits were anaesthetized to ensure the maintenance of the ODF in the oral cavity without escaping down the gastrointestinal tract. The marketed tablets (Stablon $®$ ) were administered orally (dissolved in distilled water) to group B via gastric gavage.

Blood samples for pharmacokinetic analysis were obtained immediately before drug intake and at $0.25,0.5,1$, $1.5,2,3,4,6,8$, and $24 \mathrm{~h}$ after dosing. Blood samples were collected in heparinized tubes and were centrifuged for $10 \mathrm{~min}$ at $3,000 \mathrm{rpm}$ at room temperature within $1 \mathrm{~h}$ of collection. Separated plasma was aspirated and transferred into plastic tubes and were stored at $-20^{\circ} \mathrm{C}$ until assayed.

\section{Determination of Tianeptine Sodium in Rabbit's Plasma}

The chromatographic conditions were as that described under HPLC analysis section except that the flow rate was $0.65 \mathrm{ml} / \mathrm{min}$ and the effluent was monitored at $220 \mathrm{~nm}(23)$. Tamsulosin was used as an internal standard (IS).

The calibration curve was constructed in 50-600 $\mathrm{ng} \mathrm{ml}^{-1}$ range. Calibration curves were prepared by adding various amounts $(50,100,200,400,500$, and $600 \mathrm{ng})$ of tianeptine to aliquots $(1 \mathrm{~mL})$ of drug-free plasma, and a fixed amount $(1 \mu \mathrm{g} / \mathrm{ml}))$ of the IS. Four milliliters of dichloromethane: diethyl ether (3:7) mixture was then added and the tubes were vortexed for $30 \mathrm{~s}$ and centrifuged for $10 \mathrm{~min}$ at $3,000 \mathrm{rpm}$. The supernatant was evaporated to dryness, the residue was dissolved into $200 \mu \mathrm{L}$ of the mobile phase and $20 \mu \mathrm{L}$ of this solution was injected into the HPLC system. The assay was validated for linearity, precision and accuracy. Three replicates of quality control sample at 2,000 $\mathrm{ng} \mathrm{ml}^{-1}$ were diluted to $1: 10$ with free plasma to verify the applicability of the method to determine concentrations exceeding higher levels of the calibration curve range (24).

\section{Pharmacokinetic and Statistical Calculations}

Peak concentration $\left(C_{\max }\right)$ and peak times $\left(t_{\max }\right)$ were derived directly from the experimental points. The other pharmacokinetic parameters were computed by noncompartmental analysis using WinNonlin ${ }^{\circledR}$ software (version 1.5, scientific consulting, Inc, Cary, NC, USA).

The pharmacokinetic parameters of the two tested formulae were compared by two-way analysis of variance using the software SPSS (SPSS Inc., Chicago, USA). The significance of the difference was determined at $\alpha=0.05$.

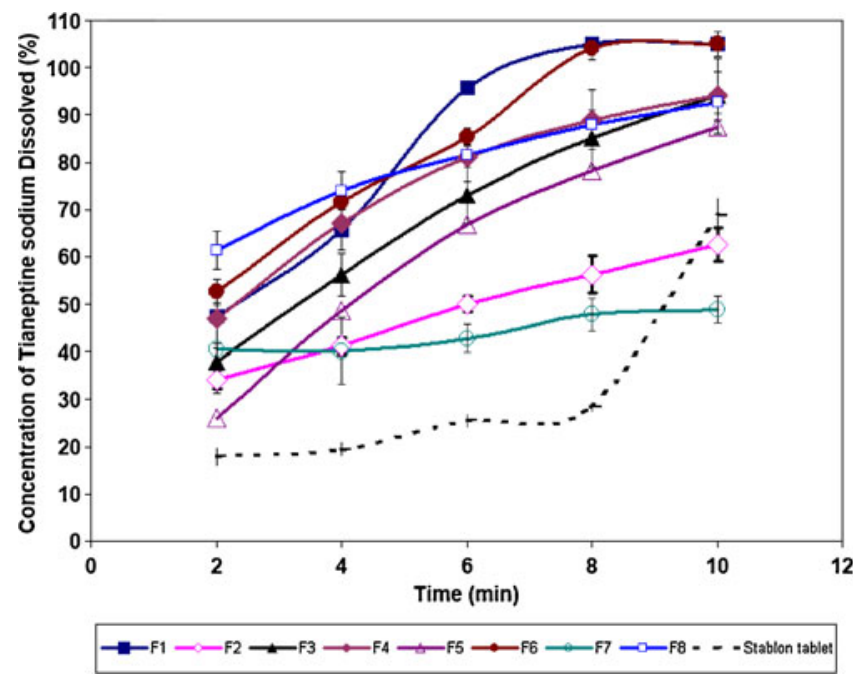

Fig. 2. In vitro dissolution profiles of tianeptine sodium from different orodispersible films in comparison to Stablon ${ }^{\circledR}$ tablet 

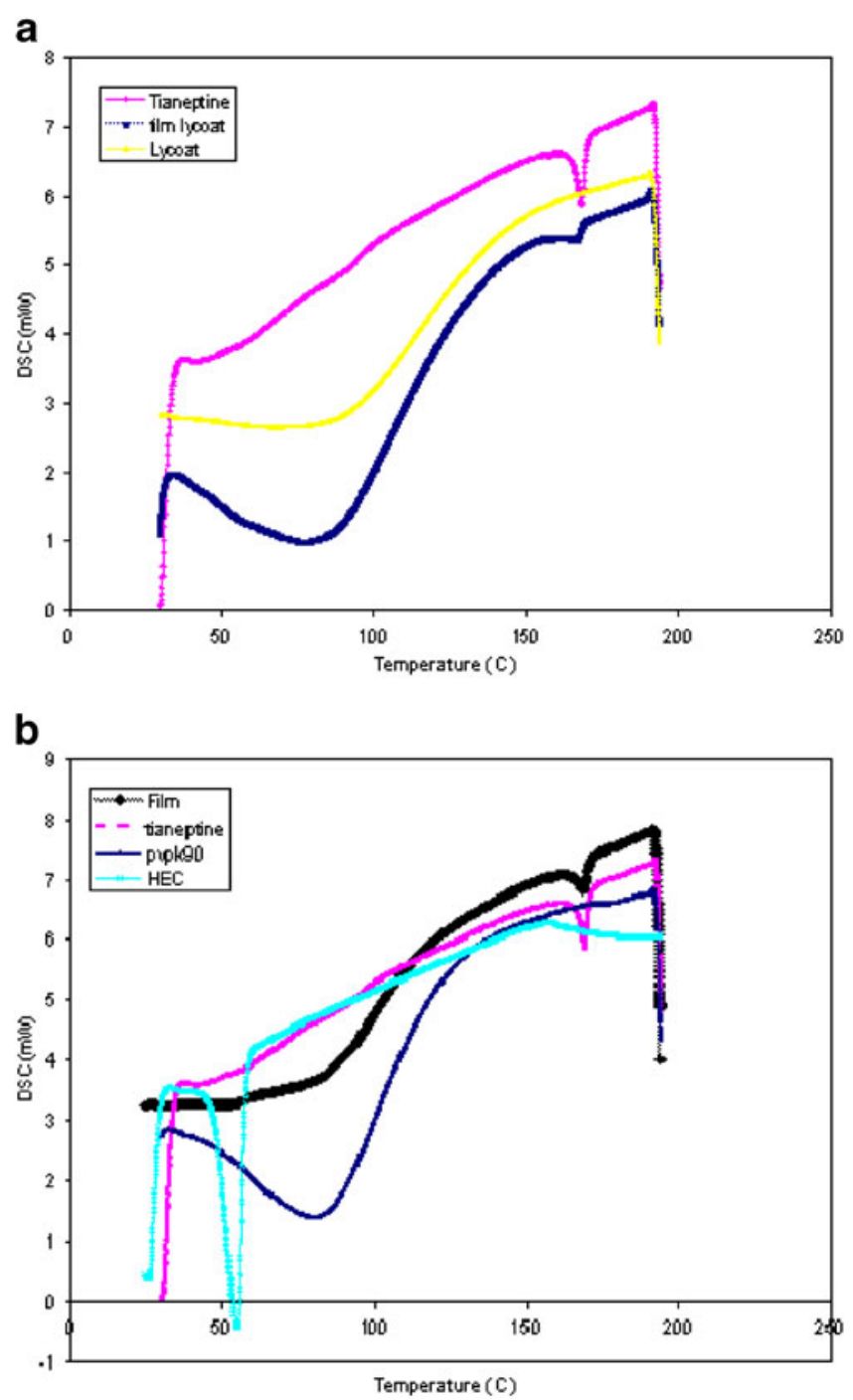

Fig. 3. DSC thermograms of ODFs F1 (a) and F7 (b)

\section{RESULTS AND DISCUSSION}

\section{Preparation and Physical Characterization of Films}

Different homogenous tianeptine sodium orodispersible films were prepared; the films are translucent, colorless, thin and soft, and with no spot found on the films. The prepared films were evaluated in terms of physico-mechanical proper- ties and the results are given in Table II. Assay of drug content at five different places in each film showed that the drug was uniformly distributed throughout the films; and were also within the required compendial specifications, i.e., within $92-107.5 \%$ (25). The average thickness of the films ranged from $0.1-0.37 \mathrm{~mm}$. In vitro disintegration time was within $60 \mathrm{~s}$ for all prepared orodispersible films except for F3 and F4 which disintegrated within $2 \mathrm{~min}$; this may be due to that F3 and F4 were harder compared with other ODFs as evident by higher EM.

Presence of moisture in films helps them from becoming dry and brittle due to plasticizing effect of water, all ODFs lose water in dry conditions and pick moisture over $60 \% \mathrm{RH}$ $(8,26)$. The ranking of moisture absorption capacity was as follows: F6 $(54.165 \% \pm 5.9)>\mathrm{F} 2(36.875 \% \pm 0.88)>\mathrm{F} 8$ $(32.855 \% \pm 6.05)>\mathrm{F} 1(31.9 \% \pm 2.02)>\mathrm{F} 5(26 \% \pm 8.48)>\mathrm{F} 7$ $(16.2 \% \pm 1.69)>$ F3 $(6.01 \% \pm 1.24)>\mathrm{F} 4(0 \%)$. These results are in accordance with Nafee et al. (27) who found that PVA buccal patches showed the least swelling behavior compared with other buccal patches prepared from different cellulose polymers; this can be attributed to the moisture barrier properties of PVA (28), also may be due to that heat treatment of PVA reduce degree of swelling due to water uptake (29).

\section{In Vitro Dissolution}

The calibration curve of tianeptine showed a linear response across the concentration range used from 10 $60 \mu \mathrm{g} \mathrm{ml} \mathrm{m}^{-1}\left(R^{2}=0.999\right)$. The assay method showed acceptable precision with C.V. $\%<7 \%$ for the intra-day assay and C.V. $\%<3$ for the inter-day assay (C.V. and the \% $\mathrm{RE}$ had to be within $\pm 20 \%$ for the lowest concentration and $\pm 15 \%$ for the upper levels.). Also, the assay method showed acceptable accuracy, assayed values were within $\pm 15 \%$ of the actual values $(95.92 \%$ to $101.09 \%)$ with relative error $<1 \%$ $(24,30)$. The results are given in Table III. The chromatogram obtained through the injection of the placebo solution did not present any peaks at the same retention time $(4.925 \mathrm{~min}$ ) of the drug (Fig. 1a and b).

It was noticed that the films got hydrated rapidly; and began to dissolute the drug within minutes. This may be due to the water solubility of the drug and the polymer. The water soluble inert fillers were reported to be used as inert carriers to form a high water soluble dispersion with active agents (31). The in vitro dissolution profiles of tianeptine sodium films are given in Fig.2.

Table IV. Intra-day, Inter-day Precision and Accuracy of the HPLC Method Used for the Determination of Tianeptine Sodium Concentration in Rabbit's Plasma

\begin{tabular}{|c|c|c|c|c|c|}
\hline \multirow[b]{2}{*}{ Concentration (ng/ml) } & \multicolumn{2}{|c|}{ Precision C.V.\% } & \multicolumn{3}{|c|}{ Accuracy } \\
\hline & Intra-day & Inter-day & $\mathrm{C}_{\text {theoretical }}$ & $\mathrm{C}_{\text {measured }}$ & $\% \mathrm{RE}$ \\
\hline 50 & 8.62 & 9.55 & 50 & 44.84067 & -10.32 \\
\hline 100 & 4.75 & 6.21 & 100 & 112.59805 & 12.6 \\
\hline 200 & 5.78 & 3.55 & 200 & 211.36548 & 5.68 \\
\hline 400 & 5.20 & 4.09 & 400 & 361.56737 & -9.61 \\
\hline 500 & 1.60 & 1.76 & 500 & 527.92798 & 5.58 \\
\hline 600 & 1.15 & 1.11 & 600 & 586.09314 & -2.32 \\
\hline
\end{tabular}




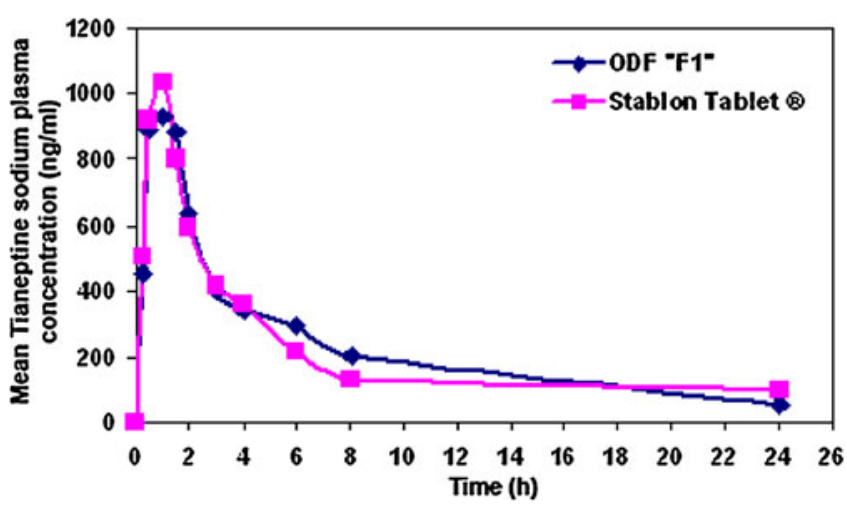

Fig. 4. Mean plasma concentration following administration of $12.5 \mathrm{mg}$ tianeptine sodium in orodispersible film (F1) and in Stablon ${ }^{\circledR}$ tablet to six rabbits

Most of the films dissolved almost completely within 10 minutes except for F2, and F7 where only 62.5 and $48.8 \%$ were dissolved, respectively, after $10 \mathrm{~min}$. However, after about $6 \mathrm{~min}$, marked differences in the tianeptine release were seen between F1 and all other formulations $(p<0.05)$.

At 6 minutes the dissolution rate $(\mathrm{mg} / \mathrm{min})$ was found to decrease in the following order F1 (15.97) > F6(14.23) > F8 $(13.6)>\mathrm{F} 4(13.5)>\mathrm{F} 3(12.2)>\mathrm{F} 5(11.13)>\mathrm{F} 2(8.33)>\mathrm{F} 7$ (7.11).

The difference in dissolution may be attributed to the differences in the composition of film-forming materials (Table I); F1 is prepared using lycoat NG73® which is a granular hydroxylpropyl starch specially designed for oral dosage forms. Lycoat NG73 can be used as the sole filmforming polymer to formulate ODFs with excellent functionality without the need of additional film-forming agent (9).

Films prepared using HEC (except F7) showed higher dissolution rate when compared with F2 prepared using HPMC. This could be explained by the fact that, HEC is more hydrophilic and possess high erosion rate when compared with HPMC. These results are in accordance with Nafee et al. (27) who prepared different mucoadhesive buccal patches of miconazole nitrate and found that the release of miconazole nitrate from HPMC patches was slower than HEC. F3 and F4 films prepared using PVA showed higher dissolution rate when compared with HPMC films. This may be due to swelling of PVA forming a gel layer on the exposed film surfaces. The loosely bound PVA molecules were easily eroded, allowing the release of the drug (32).

It was clear that the lowest dissolution rate was found in F7 prepared using HEC and 10\% PVP K90 this may be due to relatively high concentration and viscoelastic properties of
PVP K90 (33). On the other hand, it was observed that maltodextrin and lycoat RS720 (®) support rapid drug dissolution. Maltodextrin was reported to result in release of the drug immediately on contact with aqueous medium of $\mathrm{pH}$ 1.2 to 7.2 (34), and lycoat RS720 @ is known to be a free flowing modified pea starch ensuring low viscosity dispersion with immediate solubilization in water (35). DSC studies were conducted for ODFs that showed highest release (F1) and lowest release (F7); the drug showed an endothermic peak at $168.09^{\circ} \mathrm{C}$. The endothermic peak of the drug was maintained in the tested ODFs without change in position; which indicated that there was no interaction between the drug and the polymers (Fig. 3a, b). So, the difference in dissolution could be attributed to the differences in the ODFs composition.

\section{Tensile Strength}

Orodispersible film should possess moderate tensile strength, high \% elongation $(\% E)$, low EM, and high percent of drug release (6). The results revealed that all the films showed moderate tensile strength values, films of F1, F2 and F7 showed significantly highest $\% E$ compared with other formulae. F1, F7, and F8 showed significantly lowest EM. Tensile strength measurements revealed that F1 and F7 showed the highest $\% E$ and lowest EM (Table II). The test could not be applied to F6 because the film was broken at and not between the clamps of testing machine.

Based on the above results the ODF of formula F1 showing the highest dissolution rate, an in vitro disintegration time suitable for fast-dissolving dosage form, a moderate moisture uptake and satisfactory mechanical properties was chosen for subsequent comparative bioavailability study relative to a marketed tianeptine product (Stablon ${ }^{\circledR}$ tablets).

\section{Relative Bioavailability Study}

\section{Assay Method Validation}

A linear response across the concentration range used from $50-600 \mathrm{ng} \mathrm{ml}^{-1}$ was obtained $\left(R^{2}=0.9884\right)$. The assay method showed acceptable precision with C.V. \% $<9 \%$ and $<10 \%$ for the intra-day assay and the inter-day assay respectively. In addition the assay method showed acceptable accuracy with relative error $<13 \%$ and assayed values within $89.69-112.59 \%$ of the actual values. The lowest concentration $\left(50 \mathrm{ng} \mathrm{ml}^{-1}\right.$ ) which verified the accuracy and precision requirements is considered as the lower limit of quantitation (24). The results are given in Table IV. The

Table V. Mean and 90\% Confidence Intervals (CIs) for Pharmacokinetic Parameters Following Administration of 12.5 mg Tianeptine Sodium in Orodispersible Film (F1) and Stablon ${ }^{\circledR}$ Tablets to Six Rabbits

\begin{tabular}{|c|c|c|c|c|c|}
\hline \multirow[b]{2}{*}{ Parameters } & \multirow[b]{2}{*}{ Orodispersible film $($ mean $\pm \mathrm{SD})$} & \multirow[b]{2}{*}{ Stablon ${ }^{\circledR}$ tablet $($ mean \pm SD) } & \multirow[b]{2}{*}{$90 \%$ CIs } & \multicolumn{2}{|c|}{ Statistical tests $(\mathrm{p})$} \\
\hline & & & & Treatment & Period \\
\hline$C_{\max }(\mathrm{ng} / \mathrm{ml})$ & $1,115.83 \pm 181.5$ & $1,243.39 \pm 272.9$ & $85.73-95.86$ & 0.488 & 0.584 \\
\hline $\mathrm{AUC}_{0-t}\left(\mathrm{ng} \mathrm{hml}^{-1}\right)$ & $4,881.69 \pm 633.58$ & $4,402.03 \pm 718.04$ & $107.86-115.05$ & 0.700 & 0.180 \\
\hline $\operatorname{AUC}_{0-\infty}\left(\mathrm{ng} \mathrm{hml}^{-1}\right)$ & $5,288.89 \pm 822.39$ & $4,842.78 \pm 827.17$ & $107.85-111.11$ & 0.805 & 0.342 \\
\hline$t_{\max }(\mathrm{h})$ & $1.00 \pm 0.5$ & $1.00 \pm 0.5$ & - & - & - \\
\hline$t_{1 / 2}(\mathrm{~h})$ & $5.54 \pm 1.31$ & $5.24 \pm 2.18$ & $92.64-125.82$ & 0.898 & 0.943 \\
\hline
\end{tabular}


difference between theoretical quality control sample value $\left(2,000 \mathrm{ng} \mathrm{ml}^{-1}\right)$ and mean back calculated value after dilution was $10.8 \%$ ( $\pm 15 \%)(24)$.

\section{Bioavailability Parameters}

The mean tianeptine sodium plasma concentration-time profiles for the prepared orodispersible film (treatment A) and the marketed Stablon ${ }^{\circledR}$ tablets (treatment B) are shown in Fig.4. The bioavailability parameters for both formulae in addition to the statistical analysis comparing the two formulae are summarized in Table $\mathrm{V}$. The statistical comparison of $C_{\text {max }}, \mathrm{AUC}_{0-t}$, and $\mathrm{AUC}_{0-\infty}$ indicated no significant difference between the two treatments (test and reference marketed tablets), also no significant difference for period effect was observed in that study. The $90 \%$ confidence intervals for the mean ratio (test/reference) of $C_{\max }, \mathrm{AUC}_{0-t}$, and $\mathrm{AUC}_{0-\infty}$ (Table V) were within the food and drug administration criterion (80-125\%) (36). The mean ratio (test/reference) of $C_{\text {max }}, \mathrm{AUC}_{0-t}$, and $\mathrm{AUC}_{0-\infty}$ were $89.74 \%, 110.9 \%$, and $109.21 \%$, respectively. Based on the statistical inferences it was concluded that the two formulations exhibited comparable plasma level-time profiles.

\section{CONCLUSION}

The fast-dissolving orodispersible films of tianeptine sodium prepared using different film-forming materials by the solvent-casting method showed satisfactory drug dissolution and acceptable physico-mechanical characteristics.

Amongst eight formulae, the film prepared using Lycoat NG73 (F1) showed the highest dissolution rate, suitable in vitro disintegration time and satisfactory physico-mechanical properties.

In vivo study indicated absence of significant difference between $\mathrm{F} 1$ and Stablon $\AA$ tablets, both exhibited comparable drug plasma level-time profiles. Therefore, the present orodispersible film containing tianeptine sodium is considered to be potentially useful for treatment of acute depression where improved patient compliance and convenience is expected.

\section{ACKNOWLEDGEMENT}

The authors are grateful to Professor Dr. Samia Nour, Professor of Pharmaceutics and Industrial Pharmacy, Faculty of Pharmacy, Cairo University for revising the manuscript.

\section{REFERENCES}

1. Cilurzo F, Cupone IE, Minghetti P, Selmin F, Montanari L. Fast dissolving films made of maltodextrins. Eur J Pharm Biopharm. 2008;70:895-900.

2. Patel PB, Gupta GD. Fast dissolving drug delivery systems: an update. Pharminfo.net, 2006; 4.

3. Keith S. Advances in psychotropic formulations. Prog Neuropsychopharmacol Biol Psychiatry. 2006;30:996-1008.

4. Gaisford S, Verma A, Saunders M, Royall PG. Monitoring crystallization of drugs from fast-dissolving oral films with isothermal calorimetry. Int J Pharm. 2009;380:105-11.

5. Shimoda H, Taniguchi K, Nishimura M, Matsuura K, Tsukioka $\mathrm{T}$, Yamashita $\mathrm{H}$, et al. Preparation of a fast dissolving oral thin film containing dexamethasone: a possible application to antiemesis during cancer chemotherapy. Eur J Pharm Biopharm. 2009, doi: 10.1016/j.ejpb.2009.08.010.

6. Mashru RC, Sutariya VB, Sankalia MG, Parikh PP. Development and evaluation of fast-dissolving film of salbutamol sulphate. Drug Dev Ind Pharm. 2005;31:25-34.

7. Dinge A, Nagarsenker M. Formulation and evaluation of fast dissolving films for delivery of triclosan to the oral cavity. AAPS PharmSciTech. 2008;9:349-56.

8. Ahmed MG, Charyulu RN, Harish NM, Prabhu P. Formulation and in-vitro evaluation of chitosan films containing tetracycline for the treatment of periodontitis. Asian J Pharm. 2009;3:113-9.

9. Prissaux X, Josh A, Francois A, Lefevre P. Evaluation of a novel modified starch polymer in an easy to formulate thin film drug delivery system and comparison with some marketed formulations. AAPS 2007. Available at: (www.roquette-pharm.com). Accessed July 2009.

10. Defrance R, Marey C, Kamoun A. Antidepressant and anxiolytic activities of tianeptine: an overview of clinical trials. Clin Neuropharmacol. 1988;11:S74-82.

11. Khedr A. High-performance liquid chromatographic stability indicating assay method of tianeptine sodium with simultaneous fluorescence and UV detection. J Chromatogr Sci. 2007;45:305-10.

12. Uzbay TI, Kayir H, Ceyhan M. Effects of tianeptine on onset time of pentylenetetrazole-induced seizures in mice: possible role of adenosine A1 receptors. Neuropsychopharmacology. 2007;32:412-6.

13. Muniz PS, Nardi AE. Refractory pain-depression syndrome treated with tianeptine: a case report. Aust N Z J Psychiatry. 2004;38:176-82.

14. Uzbay TI. Tianeptine: potential influences on neuroplasticity and novel pharmacological effects. Prog Neuropsychopharmacol Biol Psychiatry. 2008;32:915-24.

15. Gorle AP, Gattani SG. Design and evaluation of polymeric ocular drug delivery system. Chem Pharm Bull. 2009;57:914-9.

16. Ammar HO, Ghorab M, El-Nahhas SA, Kamel R. Polymeric matrix system for prolonged delivery of tramadol hydrochloride, part I: physicochemical evaluation. AAPS PharmSciTech. 2009;10:7-20. doi:10.1208/s12249-008-9167-0.

17. Rawas-Qalaji MM, Simons FE, Simons KJ. Fast-disintegrating sublingual tablets: effect of epinephrine load on tablet characteristics. AAPS PharmSciTech. 2006;7:E1-7.

18. Cohen JL, Hubert BB, Leeson LJ, Rhodes CT, Robinson JR, Roseman TJ, et al. The development of USP dissolution and drug release standards. Pharm Res. 1990;7:983-7.

19. Kim JO, Choi JY, Park JK, Kim JH, Jin SG, Chang SW. Development of clindamycin-loaded wound dressing with polyvinyl alcohol and sodium alginate. Biol Pharm Bull. 2008;31: 2277-82.

20. Miyazaki S, Nakayama A, Oda M, Takada M, Attwood D. Drug release from oral mucosal adhesive tablets of chitosan and sodium alginate. Int J Pharm. 1995;118:257-63.

21. Mannila J, Järvinen T, Järvinen K, Tarvainen M, Jarho P. Effects of RM-beta-CD on sublingual bioavailability of delta9-tetrahydrocannabinol in rabbits. Eur J Pharm Sci. 2005;26:71-7.

22. Mannila J, Järvinen $T$, Järvinen $K$, Tervonen J, Jarho $P$. Sublingual administration of delta9-tetrahydrocannabinol/betacyclodextrin complex increases the bioavailability of delta9tetrahydrocannabinol in rabbits. Life Sci. 2006;78:1911-4.

23. Moffat A, Osselton MD, Widdop B, Galichet LY. Clarke's Analysis of Drugs and Poisons, electronic version. 3rd ed. London: Pharmaceutical Press; 2004.

24. Gaulier JM, Marquet P, Lacassie E, Desroches R, Lachatre G. High-performance liquid chromatographic determination of tianeptine in plasma applied to pharmacokinetic studies. J Chromatogr. 2000;748:407-14.

25. British Pharmacopoeia III, Her Majesty's Stationery Office Ltd., London, 2003. pp. 2598-2599

26. Arora P, Mukherjee B. Design, development, physicochemical, and in-vitro and in-vivo evaluation of transdermal patches containing diclofenac diethylammonium salt. J Pharm Sci. 2002;91:2076-89.

27. Nafee NA, Ismail FA, Boraie NA, Mortada LM. Mucoadhesive buccal patches of miconazole nitrate: in vitro/in vivo performance and effect of ageing. Int J Pharm. 2003;264:1-14. 
28. Chen L, Imam SH, Gordon SH, Greene RV. Starch-polyvinyl alcohol crosslinked film performance and biodegradation. J Environ Polym Degrad. 1997;5:111-7.

29. Katz MG, Wydeven T. Selective permeability of PVA membranes. II. Heat-treated membranes. J Appl Polym Sci. 1982;27:79-87.

30. Guidance for Industry, Bioanalytical Method Validation, U.S. Department of Health and Human Services Food and Drug Administration. 2001.

31. Chakravorty S, Hariharan V. Mouth dissolvable and meltable, and water dispersible delivery formulation USPC Class: 514242 IPC8 Class: AA61K3153FI.

32. Korsmeyer RW, Gurny R, Doelker E, Buri P, Peppas NA. Mechanisms of solute release from porous hydrophilic polymers. Int J Pharm. 1983;15:25-35.
33. Diaz del Consuelo I, Falson F, Guy RH, Jacques Y. Ex vivo evaluation of bioadhesive films for buccal delivery of fentanyl. J Control Release. 2007;122:135-40.

34. Daniel JZ, Michael DR, Albert H. Edible film formulations containing maltodextrin, 2004; US patent: 6,740,332.

35. Prissaux X, Josh A, Dussautois C, Le Bihan G, Lefevre P. Functional advantages of a novel modified starch over HPMC in aqueous film coating of tablets. AAPS 2006. Available at: (www. roquette-pharm.com). Accessed July 2009.

36. Zou J, Di B, Wu CY, Hu Q, Li JH, Zhu Y, et al. Pharmacokinetic and bioequivalence comparison of a single 100-mg dose of cefteram pivoxil powder suspension and tablet formulations: a randomized-sequence, open-label, two-period crossover study in healthy Chinese adult male volunteers. Clin Ther. 2008;30:65460. 